http://dx.doi.org/10.18778/2196-8403.2013.19

\title{
NACHRUFE
}

\section{Krzysztof Lipiński}

Er starb am 25. Februar 2013 in einem Alter, in dem ein ausgewiesener und schöpferischer Universitätsprofessor noch sehr viele Pläne besitzt. Man hörte zwar, dass es ihm in letzter Zeit nicht gut ging, und doch kam die Nachricht von seinem Tod für die, die ihn kannten und mochten, recht überraschend. Professor Krzysztof Lipiński wurde 1957 in Rzeszów geboren, studierte Germanistik an der Jagiellonen-Universität Krakau und wurde nach einem ausgezeichneten Studienabschluss als Assistent am Lehrstuhl für Germanische Philologie angestellt. Er war Schüler der bekannten Krakauer Literaturwissenschaftlerin Professor Olga Dobijanka, die ihn in seinen wissenschaftlichen Vorhaben betreute und fachlich unterstützte. Professor Lipiński war vor allem ein hochbegabter und aufgeschlossener Literaturhistoriker. Da er zugleich selbst Gedichte und Prosawerke schrieb und publizierte, machte er sich auch bald einen Namen als talentierter Lyrikübersetzer. Das Dichten und Übersetzen brachte ihn schließlich zur kreativen Beschäftigung mit der Übersetzungswissenschaft. In der germanistischen Welt war er aber vornehmlich durch seine eindringlichen und weiterführenden Studien in der Literaturforschung, die er sowohl in deutscher als auch in polnischer Sprache veröffentlichte, bekannt. Sein wissenschaftliches Interesse galt der modernen deutschsprachigen Lyrik, der deutschen Klassik und der Literatur aus Österreich. Auf dem Studium dieser Fachrichtungen baute er seine gesamte wissenschaftliche Laufbahn auf.

Krzysztof Lipiński promovierte für polnische Verhältnisse recht früh mit einer unkonventionellen Abhandlung über die poetologischen Grundlagen der Lyrik von Georg Trakl, in der er versuchte, die Kunst des Übersetzens mit der Kunst der Interpretation in Einklang zu bringen. Als Gutachter dieser Dissertation habe ich ihn damals persönlich kennengelernt und sofort sein wissenschaftliches Potential und seine dichterische Sensibilität erkannt. Da wir den gleichen Forschungsinteressen nachgingen, sollten sich später unsere wissenschaftlichen Wege noch mehrmals kreuzen. Ich habe wohlwollend seine Habilitationsschrift über Goethes „Faust“ als Übersetzungsvorlage (1990) beurteilt und wurde danach als Gutachter beim Verfahren für seine Professur von der Jagiellonen-Universität eingeladen. Wir trafen uns auch oft bei literarischen Kongressen und Symposien, meist im Ausland, das letzte Mal bei der Sitzung der Österreichischen-Kafka-Gesellschaft, in der wir 
beide aktiv waren. Aus den Begegnungen mit den Texten von Krzysztof Lipiński sind mir besonders jene im Gedächtnis geblieben, in denen der Autor versucht hat, seine wissenschaftlichen Thesen durch eigene übersetzerische Tätigkeit zu unterstützen, so war es mit seinen Trakl-Studien, seinen Rilke-Aufsätzen und Goethe-Abhandlungen. Er war ein feinfühliger Nachdichter, der seinen Übersetzungen stets tiefschürfende philologische Studien voranstellte. Obwohl es in Polen mehr als zehn gute Faust-Übersetzungen gibt, habe ich seinerzeit für die polnische Ausgabe von Goethes Werken gerade seine Übertragung gewählt, nicht weil ich den Übersetzer gut kannte und ihn in manchen translatorischen Vorhaben beraten habe, sondern weil mir von allen anderen polnischen Faust-Übertragungen seine dem Geist von Goethe am nächsten zu stehen schien. Als Übersetzer hatte er die besondere Gabe, sich auf eine künstlerisch brillante Art in die Denkweise und in die Poetologie des übersetzten Dichters zu versetzen.

Mit Lipiński verband mich auch die Faszination für die österreichische Literatur; besonders sachkundig und methodologisch weiterführend fand ich seine Aufsätze über Rainer Maria Rilke, Franz Kafka, Joseph Roth und überhaupt seine Bücher zum Komplex der deutschsprachigen und polnischen Literatur über Galizien. Ich denke hier insbesondere an den fundierten Sammelband Auf der Suche nach Kakanien, der im Jahr 2000 in Österreich erschien. Dank dieser Studien, aber vor allem dank seiner versierten TraklForschungen war Krzysztof Lipiński auch im Ausland - in Österreich, in Deutschland und in der Ukraine - als angesehener polnischer Literaturwissenschaftler bekannt, was die lange Liste seiner Zitierungen in diesen Ländern dokumentiert. Die letzten Jahre seiner Arbeit verbrachte er an der Universität in Rzeszów, in seiner Heimatstadt, wo er auch gestorben ist. Er wird der polnischen Germanistik fehlen, besonders seine kompetenten literaturhistorischen und translatologischen Bücher, seine kultivierten Nachdichtungen und seine sonderbare, leicht ironische Art des wissenschaftlichen Diskurses. Seine polnischen und ausländischen Kollegen wissen, dass er noch viel für die polnische und internationale Germanistik zu tun hatte. Auch Convivium trauert um ihn.

Stefan H. Kaszyński, Poznań 


\section{Eugeniusz Tomiczek}

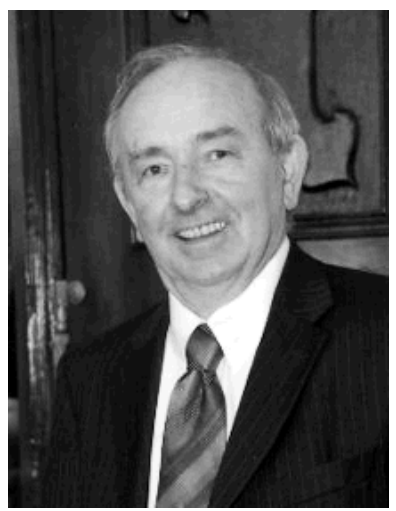

Die europäische Germanistik hat einen großen Verlust erlitten: Am 12. März 2013 verstarb nach langer Krankheit im Alter von 69 Jahren Prof. dr hab. Eugeniusz Tomiczek, in den Jahren 1987-1990 Prodekan und 1990-1993 Dekan der Philologischen Fakultät an der Universität Breslau, 1993-2012 Direktor des dortigen Instituts für germanische Philologie, Leiter des Lehrstuhls für Angewandte Linguistik, Mitglied des wissenschaftlichen Beirats der Zeitschrift Convivium, ein hochrangiger Wissenschaftler, guter Soziolinguist und hervorragender Didaktiker, unser Freund.

Der Verstorbene blieb sein ganzes Leben lang seinem Schlesien treu. Breslau wurde, neben Tomiczeks Geburtsort Teschen, zur zweiten Heimatstadt: Hier absolvierte er sein Studium am Institut für Germanistik (1967), promovierte zu lexikalischen Innovationen in der deutschen Gegenwartssprache (1974) und erwarb (1983) die Venia Legendi nach der glänzenden Habilitation über das deutsche und das polnische adressative System, die heute einhellig als qualitative Zäsur in der Entwicklung der polnischen Soziolinguistik anerkannt wird. Neben seiner wissenschaftlichen Leidenschaft, Wissbegierde und Akribie zeigte Tomiczek als Dekan und Institutsdirektor auch sein organisatorisches Talent: Dank kluger Entschlüsse und alle damaligen Denkschablonen sprengender Ideen führte er sein Institut durch die mageren Transformationsjahre sicher hindurch und in den Prosperitätsjahren der polnischen Germanistik baute er die Größe des Instituts für Germanistik aus. Tomiczek war es, dem die Breslauer Germanistik den Ruf der größten Auslandsgermanistik verdankte.

Seine Freunde behalten ihn in Erinnerung als einen Menschen, der wissenschaftliche, administrative und gesellschaftliche Funktionen in gekonnter Weise zu verbinden verstand. Tomiczek war Vorstandsmitglied der DeutschPolnischen Gesellschaft der Universität Breslau, Mitglied des Internationalen Wissenschaftlichen Rates des Instituts für Deutsche Sprache in Mannheim, Mitglied des Germanistenverbands Polen, Mitglied der Polnischen Linguistischen Gesellschaft, Mitglied der Societas Humboldtiana Polonorum, der Organisation polnischer Alexander-von-Humboldt-Stipendiaten. Für sein wissenschaftliches, didaktisches und soziales Engagement wurde er mehrfach 
mit Orden und Medaillen ausgezeichnet, so mit dem Goldenen Verdienstkreuz, der Medaille für Nationale Bildung und dem (deutschen) Bundesverdienstkreuz am Bande.

Die germanistische Gemeinschaft aber hat vor allem einen guten Kollegen verloren. Eugeniusz Tomiczek war ein Mensch von bestechender menschlicher Güte und Wärme.

Mögest Du in Frieden ruhen, treuer Freund!

Lesław Cirko, Wrocław 